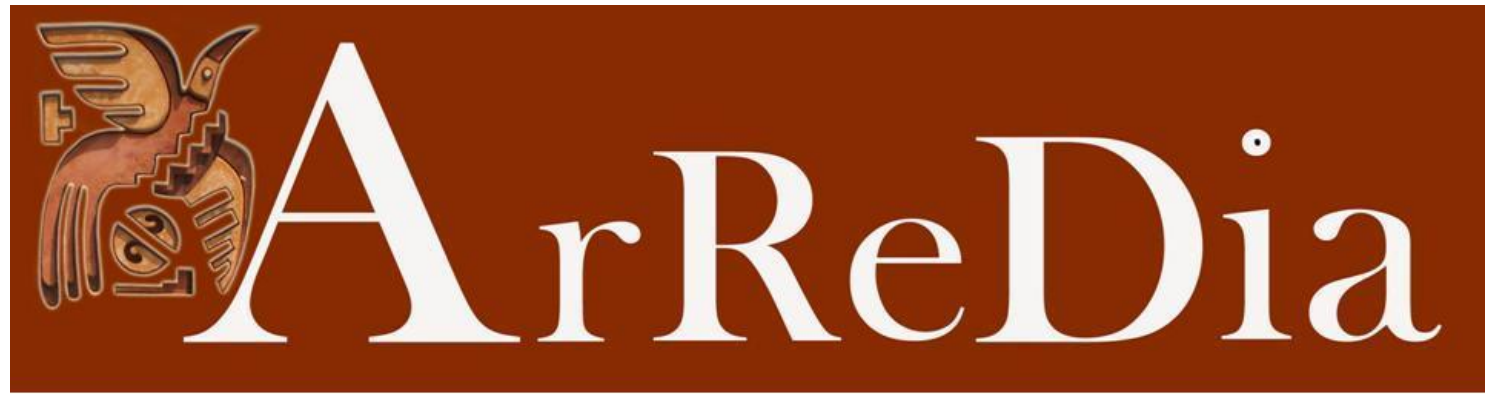

Revista da Faculdade de Comunicação, Artes e Letras / UFGD

\title{
O ROMANCE HISTÓRICO FIGURA NA SOMBRA: a história e a ficção na literatura de Assis Brasil
}

\section{The historical romance figure in the shadow: history and fiction in the literature of Assis Brasil}

\author{
Camilo Mattar Raabe ${ }^{i}$ \\ Pontifícia Universidade Católica do Rio Grande do Sul
}

\begin{abstract}
RESUMO: Figura na sombra (2012), romance do escritor Luiz Antonio de Assis Brasil, retrata a vida do aclamado botânico Aimé Bonpland, em especial sua relação com Alexander von Humboldt, com quem realizou expedições na América e elevou-se aos mais honrados nomes da academia, e sua posterior reclusão na América do Sul, onde viveu seus últimos dias confundindo-se entre os trabalhadores do campo, obcecado pelo cultivo da erva-mate. A precisão de Assis Brasil com a produção ficcional ambientada no passado histórico e fundada por densa pesquisa desenvolve-se desde a década de 1970, distinguindo-se do modelo de romance histórico proposto por György Lukács e aproximando-se das leituras de Seymour Menton e Linda Hutcheon sobre as novas modalidades de romances históricos. O objetivo do presente estudo é considerar a estrutura constitutiva do romance Figura na sombra buscando precisar o modo como a ficção relaciona-se com a história, análise precedida por uma panorâmica leitura da relação entre história e a ficção.
\end{abstract}

Palavras-chave: Romance histórico. Figura na sombra. Luiz Antônio de Assis Brasil.
ABSTRACT: Figura na sombra (2012) is a novel written by Luiz Antônio de Assis Brasil about the life of the world-renowned botanic Aimé Bonpland, specially his relation with Alexander von Humboldt, with whom he made expeditions in America and studies honored by the academy; also his later reclusion in South America, living with common workers in rural activities, obsessed by yerba mate cultivation. Since the 1970s Assis Brasil develops with accuracy his fictional production set in the historical past and founded by dense research, distinguishing itself from the historical novel model proposed by György Lukács, approaching the Seymour Menton and Linda Hutcheon readings on the new modes of historical novels. The focus of the present study is to consider the construction of the novel Figura na sombra focusing on how fiction relates to history, analysis preceded by a broad and superficial reading about history and fiction relation.

Key words: Historical novel. Figura na sombra. Luiz Antônio de Assis Brasil. 


\section{Introdução}

Figura na sombra (2012), romance do escritor Luiz Antonio de Assis Brasil, retrata a vida do aclamado botânico Aimé Bonpland, em especial sua relação com Alexander von Humboldt, com quem realizou expedições na América e elevou-se aos mais honrados nomes da academia, e sua posterior reclusão na América do Sul, onde viveu seus últimos dias confundindo-se entre os trabalhadores do campo, obcecado pelo cultivo da erva-mate. A precisão de Assis Brasis com a produção ficcional ambientada no passado histórico e fundada por densa pesquisa desenvolve-se desde a década de 1970, com o romance Um quarto de légua em quadro (1976). Em Figura na sombra, quarto volume da série Visitantes ao Sul, a fascinante história de Bonpland é construída em uma narrativa bem elaborada, distinguindo-se do modelo de romance histórico proposto por György Lukács (2011) e aproximando-se das leituras de Seymour Menton (1993) e Linda Hutcheon (1991) sobre novas modalidades de romances históricos. O presente estudo considera a estrutura constitutiva do romance Figura na sombra quanto ao modo como a ficção e a história estão relacionadas, influenciando a composição técnica do romance e como conduzirá o leitor pela narrativa. Tal análise será precedida por uma leitura panorâmica da relação entre história e ficção, das concepções da Grécia Antiga a leituras contemporâneas.

Os debates sobre a relação entre a história e a ficção remetem à Grécia Antiga, nas palavras de Aristóteles: "não é ofício de poeta narrar o que aconteceu; é sim, o de representar o que poderia acontecer, quer dizer: o que é possível segundo a verossimilhança e a necessidade". O que difere o historiador do poeta não é a forma como se escreve, se em prosa ou em verso, mas o fato de que "diz um as coisas que sucederam, e outro as que poderiam suceder". Nesse sentido, Aristóteles traça uma distinção entre a poesia (criação) e a história, a primeira focada no universal, "atribuir a um indivíduo de determinada natureza pensamentos e acções", a segunda foca no particular, condicionada pela realidade histórica e sua sucessão linear de escrita (ARISTOTÉLES, 1986, p. 115-116).

Na Grécia Antiga, havia uma distinção consciente entre história e literatura, fronteiras que, segundo Peter Burke (1987, p. 109), tenderam a ser minimizadas na Idade Média, quando "textos que poderíamos colocar do lado 'ficção' da fronteira eram 'história' para leitores medievais", sofrendo novamente uma segmentação radical no período renascentista, com um "retorno aos padrões clássicos" por humanistas que "fizeram distinções explícitas entre história e ficção". Para o teórico, o início do 
romance histórico desenvolveu-se a partir do século XVII, especialmente em países europeus, tendo os humanistas a atenção voltada para ter certeza de que os dados históricos presentes em seus romances eram "corretos" (Burke, 1987, p. 110), mesmo tendo consciência de que tais detalhes não eram relevantes para o enredo das obras ficcionais. $\mathrm{O}$ estudioso considera que apenas no século XIX o gênero ganhou reconhecimento por críticos e leitores, bem como surgiram novos autores dedicados a escrever seus romances a partir de temáticas históricas, aproximando-se do modelo proposto por Lukács.

O romance histórico (2011), de Lukács, é obra fundamental para o estudo do romance histórico. Para o teórico, tal modalidade surgiu no início do século XIX, por volta da queda de Napoleão, mais precisamente com Waverley (1814), de Walter Scott, quando o elemento especificamente histórico foi introduzido: "o fato de a particularidade dos homens ativos derivar da especificidade histórica de seu tempo" (p. 33). O romance histórico do século XIX serviu como ferramenta para a afirmação da consciência nacional, familiarizando os leitores com seu passado em um momento em que as nacionalidades europeias e norte-americanas se definiam e primavam pela busca de uma identidade nacional.

Baseando-se principalmente nas obras de Walter Scott, Lukács (2011) apresenta uma série de características próprias do romance histórico em sua forma clássica. De modo resumido, eles traçam grandes painéis históricos, organizando-se segundo a ordem cronológica dos fatos e narradas com a aparente imparcialidade da terceira pessoa, procedimentos semelhantes ao da história; as personagens principais são sempre fictícias, representativas de um tipo social, e as personalidades históricas, quando presentes, são apresentadas apenas como pano de fundo, de modo a conferir, junto com dados e detalhes históricos, veracidade à narrativa e à história que apresenta.

A partir do século XX - e com a contribuição da chamada École des annalles - o conceito de história começa a sofrer transformações, o caráter de fechamento da história oficial é questionado em prol de uma abertura de fontes e multiplicidade de vozes, começa a ser questionada a possibilidade de conhecimento da verdade histórica, o caráter cíclico da história e a incapacidade de sua representação. Se só é possível conhecer o passado por meio de vestígios textualizados, é porque há um lapso entre o acontecimento e o fato: do acontecimento não temos conhecimento, apenas dos fatos históricos, essencialmente discursivos. 
Hayden Whyte, em Meta-história, cuja primeira edição foi em 1973, foi pioneira na associação da narrativa histórica à narrativa ficcional, desconstruindo os conceitos aristotélicos de separação entre o poeta e o historiador, considerando que tal concepção da tarefa do historiador “obscurece o grau de 'invenção' que também desempenha um papel nas operações do historiador", uma vez que "o historiador arranja os eventos da crônica dentro de uma hierarquia de significação ao atribuir aos eventos funções diferentes como elementos da estória" (WHITE, 2008, p. 22).

Ao longo do século XX, o romance histórico vai ganhando uma nova dimensão, numa evolução que segue em paralelo às transformações ocorridas no âmbito da historiografia. Na América Latina, Seimour Menton (1993) avalia um corpus novo na relação entre história e ficção, o qual intitula novo romance histórico, tendo como principal exponente Alejo Carpentier - que já em 1949 publicou El reino de este mundo -, consolidando-se a partir do final da década de 1970. Linda Hutcheon (1991), num corpus distinto - englobando a literatura europeia e norteamericana -, avalia o que intitula metaficção historiográfica, num levantamento de pontos norteadores próximos das conclusões de Menton sobre a nova modalidade de romance histórico que se desenvolve especialmente no último quarto do século XX.

Numa espécie de oposição aos princípios do romance histórico clássico proposto por Lukács, é possível determinar características gerais dos corpora avaliados por Menton e por Hutcheon, os quais, em consonância, demonstram a espontaneidade das manifestações artísticas em meio aos acontecimentos culturais. Sob o signo da impossibilidade da apreensão da verdade histórica e até mesmo da realidade, os romances apresentam distorções conscientes da história, em muitos casos ficcionalizando personagens históricos como protagonistas; a metaficção está presente, apresentando comentários do narrador sobre o processo de criação, bem como a intertextualidade e os conceitos bahktinianos de dialogismo, carnavalização, paródia e heteroglosia.

No Brasil, a partir da década de 1970, acentuou-se a produção de romances que tematizavam a história brasileira, no entanto já se distanciavam das qualidades ortodoxas do romance histórico proposto por Lukács. O conjunto produzido no final do século passado pode ser polarizado entre narrativas que focalizam acontecimentos integrantes da história oficial e, por vezes, definidores da própria constituição física das fronteiras brasileiras, ou as que promovem a revisão do percurso 
desenvolvido pela história literária nacional, casos em que, em vias de regra, os protagonistas são personalidades da história oficial brasileira ou nomes da história literária nacional (BAUMGARTEN, 2000). Na produção do novo século, verificou-se que se intensifica a revisitação da história literária e que se acrescenta outra tônica: o uso do discurso de memórias como recurso ficcional (WEINHARDT, 2015).

Luiz Antônio de Assis Brasil é um dos representantes mais significativos da produção de romances históricos brasileiros. Estreando em 1976 com Um quarto de légua em quadro, o escritor gaúcho conta com 18 romances, todos com configurações ficcionais sobre um passado histórico, por vezes lembrando os moldes do romance histórico clássico, no entanto introduzindo inovações no gênero em construções bem elaboradas que transitam entre a revisão da historiografia nacional e também literária. No sentido da relação da história e a ficção em suas composições, Assis Brasil, em entrevista cedida a José Pinheiro Torres presente no site do escritor, considera:

\begin{abstract}
O romance histórico tradicional, ao estilo de Scott e Herculano, não se pratica mais; pelo menos, se pratica pouco - e de má qualidade. No denominado "novo romance histórico" - que Linda Hutcheon chama de "metaficção historiográfica" -, a história é sempre pretexto, e é deformada, reinterpretada, discutida e, até, criada. Imagino ter feito, e com certa frequência, essa segunda modalidade, com recurso à paródia, ao pastiche e, uma ou duas vezes, ao plágio burlesco. Penso, contudo, que é um capítulo encerrado em meu trabalho. Hoje me preocupa, mais que tudo, a fiç̧ão. Mesmo que os plots estejam situados num tempo pretérito, isso é apenas uma opção do escritor: o passado me dá maior liberdade criadora, e as emoções e paixões me parecem mais autênticas. (BRASIL, s/d).
\end{abstract}

Consoante ao afirmado nas palavras de Assis Brasil, o romance Figura na sombra parece ter como principal foco a intimidade (sobretudo no âmbito psicológico) de Aimé Bonplant, a reconstrução de seu drama pessoal mais do que a reconfiguração de sua trajetória, figura que, por mais que tenha ficado à sombra de Humboldt, é reconhecida internacionalmente e obteve grande influência e reconhecimento em sua época. Englobando ampla gama de personalidades históricas - como Humboldt, Josefina, Thomas Jefferson, o ditador Francia, Avé-Lallemant e contextualizando espaços e acontecimentos relevantes da história regional e internacional, o drama pessoal ganha uma dimensão que encara a história em diversos aspectos, os quais intenta-se apreciar ao longo do estudo. 
O romance ilustra a vida de Bonpland, a qual pode ser dividida em quatro partes: seu nascimento em La Rochelle, em 1773, sua juventude e formação acadêmica em Medicina aliada a seu apreço à botânica; a viagem que empreende com Alexander von Humboldt ao Novo Mundo, entre os anos de 1799 e 1804; seu retorno como celebridade à França, seu envolvimento com a Imperatriz Josefina e consequente distanciamento de Humboldt e sua filosofia iluminista; o retorno definitivo à América, em 1816, sua admiração obsessiva pela erva-mate, sua prisão no Paraguai pelo ditador Francia e seus últimos dias em sua Estância de Santa Ana, em Corrientes, confundido com peões, até sua morte em 1858.

O texto articula-se por meio de duas histórias paralelas. A primeira delas engloba a visita de Robert Christian Avé-Lallemant à Estância de Santa Ana a fim conhecer e prestar suas reverências ao botânico francês, que morreria menos de um mês depois ${ }^{1}$. Narrada em terceira pessoa no tempo presente, construído com constantes discursos diretos, apresenta excertos da história da vida de Bonpland contada por ele mesmo, foco da conversa entre eles - especialmente a relação com Humboldt, amizade que tinham em comum. Composta pelo prólogo, quatro "entreatos" e o epílogo (que não é o final da obra), todos introduzidos pela indicação do local e do ano, essa primeira parte sugere certo caráter de relato memorialístico e autobiográfico à história de Bonpland, a qual ganhará outra dimensão ao longo dos demais capítulos.

A segunda história desenvolve, de certo modo em atos, a história da vida de Bonpland introduzida por ele mesmo no diálogo com o visitante, distanciando-se da construção própria de uma autobiografia. Apresentando da juventude e formação intelectual até sua morte, posterior ao encontro com Avé-Lallemant, a narrativa desenvolve-se em terceira pessoa, porém com forte presença do discurso direto, quando as palavras de Bonpland - mas também de terceiros - buscam legitimar a veracidade da história colocada, tarefa à qual contribuem contextualizações históricas e descrições detalhadas do espaço (interior e exterior) e da cultura (intelectual como material) da época. Essa história paralela desenvolve-se em 73 capítulos numerados e por "Prisão de vidro", inserido como um capítulo paralelo e com uma construção peculiar.

Enquanto o encontro com Avé-Lallemant encerra-se em oito horas, o desenvolvimento da história de Bonplant segue de modo linear, em consonância com o relato autobiográfico introduzido pelo prólogo e

\footnotetext{
${ }^{1}$ A visita a Bonpland foi relatada em Viagem pelo Sul do Brasil no ano de 1858, de Avé-Lallemant.
} 
ponderado, paulatinamente, pelos entreatos e pelo epílogo. Para dar conta da trajetória de Bonpland em seu retorno à França, entre 1804 e 1815 período em que assume a superintendência do Château de Malmaison -, "Prisão de vidro" apresenta uma cena de 1849, quando Bonpland, em Porto Alegre, é atendido na Santa Casa por um médico conterrâneo e antigo conhecido, com quem, através de um diálogo estimulado por segundas intenções, rememora como conheceu Napoleão e Josefina, assim como sua estadia na Malmaison, apaixonado pela imperatriz.

"Prisão de vidro", de modo curioso, tem uma estrutura semelhante à dos capítulos que dão conta da visita de Avé-Lallemat, dotados de constantes diálogos, os quais, ao contrário dos capítulos numerados, tem a fala de Bonpland introduzida por $<<>$, enquanto a dos demais personagens apresenta-se por travessões. Narrado em terceira pessoa, apresenta uma mudança na vida de Bonpland, quando é tomado por concepções românticas oriundas de Josefina, as quais o levam a romper com Humboldt, com a redação de Voyage aux Régions Équinoxiales $d u$ Nouveau Continent (Viagens às regiões equinociais do novo continente), com a prisão de vidro à qual era submetido pela sombra do barão e da qual tentou livrar-se em sua viagem definitiva à América Latina. Essa mudança é representada na estrutura do romance: enquanto até então os capítulos apresentam-se narrados no pretérito (exceto pelo de número XX), a partir de "Prisão de vidro" são apresentados no presente (apenas tendo o capítulo LI como exceção, no tempo futuro), além do nome do botânico ser modificado de Aimé para Amado, palavra que traduz ao português o nome originalmente grafado em francês.

A introdução de um narrador onisciente tem papel importante ao longo de toda a narrativa. De acordo com cada etapa e local da vida de Bonpland, o narrador desenvolve contextualizações históricas importantes, como o caso da Revolução Francesa, a qual foi vivenciada pelo protagonista enquanto estudava medicina e, paralelamente, botânica. $\mathrm{O}$ avanço da ciência sob a ótica iluminista é ilustrado com referências à ciência da catalogação de Lamarck e o desenvolvimento do Muséum d'Histoire Naturelle, por exemplo, a Pinel e o manicômio da Salpetrière, apresenta discursos diretos como os de Xavier Bichat e Corvisat em suas aulas, contribuindo para uma contextualização histórica num complexo que engloba acontecimentos importantes, a geografia e a mentalidade cultural da época. Aliadas à formação acadêmica são apresentadas leituras que Bonpland fazia em determinados momentos de sua vida, assim como sua predileção musical, ilustrando uma complexa atmosfera intelectual e que influenciou a formação do médico-botânico, como o caso recorrente 
de referências a Chateaubriand, citado até em francês mais de uma ocasião.

Bonpland vivenciou momentos históricos importantes na Europa e na América, numa época intensa de ampliação de horizontes científicos e geográficos. Após sua viagem com Humboldt e o clamor advindo de sua viagem à América, sua pessoa ganha um reconhecimento que o leva a relacionar-se com personalidades e momentos históricos que, consequentemente, dão abertura para uma contextualização pela parte do narrador, numa revisitação - pode-se dizer revisão - historiográfica. É o caso do enaltecimento de Bonpland à sombra de Humboldt, da escravidão, da figura de Napoleão como "ogro" e da Imperatriz Josefina como mulher que o levou ao desvario, da precariedade da Santa Casa de Porto Alegre, sem uma sonda urológica disponível, do ditador doutor Francia e a independência do Paraguai, da primeira alcunha científica da erva-mate como ilex humboldtiana, do auxílio de Bonpland à Revolução Farroupilha a pedido de Bento Gonçalves, da definição das fronteiras que delimitavam o Rio Grande do Sul, da herança das missões jesuíticas e a situação indígena etc.

Contribuindo para a representação do momento histórico, a indumentária sofre desenvolvidas descrições, ambientando e legitimando a narrativa segundo o momento histórico a retratar - mas também impressionando o leitor com a simplicidade com que Bonpland viria a vestir-se nas últimas décadas de sua existência. Enquanto as descrições são precisas e conferem certa palpabilidade às cenas, o narrador e a perspectiva pessoal de Bonpland conferem à narrativa uma aproximação da intimidade dos personagens históricos, vindo a configurar uma dimensão em que seres quase míticos aparecem humanos aos olhos do leitor. Dramas pessoais (o do protagonista e os de outros a ele atrelados) ganham espaço, chegando o narrador a adentrar esferas psicológicas, numa intenção de dar vida a uma perspectiva negligenciada pela historiografia e que leva os leitores a uma maior possiblidade de empatia pelas figuras históricas e pelo enredo em questão.

Para a introdução a este universo pretérito, é importante salientar que a linguagem do romance aproxima-se da falada na época, não apenas nos discursos diretos, mas, de certa maneira, também na linguagem e no imaginário do narrador, mesmo colocando-se adiante do tempo histórico retratado. Nesse sentido, já no prólogo, o narrador faz questão de justificar a linguagem que expressa, ao menos no que tange aos discursos diretos de Bonpland: 
Mesmo que Don Amado Bonpland diga "o sol deita-se violáceo no horizonte das águas atlânticas", trata-se de uma linguagem natural a quem muito leu. Essas palavras também não soam artificiais a Avé-Lallemant, fruto tardio do Romantismo alemão, uma espécie de fim de raça, admirador de Schiller e Herder. (2012, p. 17).

A linguagem ajuda a construir o universo intelectual da época, o modo de pensar e de ver o mundo, para o qual auxiliam uma série de referências e intertextos, entre os quais há a presença de línguas estrangeiras como francês, espanhol, alemão, inglês, latim e guarani. Notase o modo como se pronuncia o narrador na citação precedente, com a tendência a desenvolver e explicar questões históricas e do próprio arranjo das fontes, denotando uma consciência sobre o processo narrativo, por vezes adiantando à narrativa dos fatos suas consequências futuras, ou até mesmo atribuindo a eles um juízo ou ponderação: "Era o que merecia e desejava." (p. 189); "Cada qual sabe da grandeza do outro." (p. 208).

No romance, é recorrente o intento - por parte do narrador - de legitimar a história contada a partir de referências em que transparece a pesquisa realizada para elaboração do romance. Nesse sentido, há uma gama de discursos distintos articulados pelo narrador, sugerindo fontes consultadas: "Glória das ciências botânicas, doctor honoris causa por várias universidades europeias, Don Amado Bonpland é, como escreveu um naturalista de Ansbach, lembrado de Kaspar Hauser, um novo aenigma sui temporis." (p. 15); "Aos 85 anos, este homem não aceita conselhos nem ajuda - assim registrará Avé-Lallemant em seu diário e, depois, no livro que publicará em Leipzig no ano seguinte" (p. 16); “Acerca de Humboldt, assim escreveu a filha do marquês (...)” (p. 95).

A construção do romance, própria da heteroglosia bakhtiniana, abriga referências já comentadas a personalidades culturais e a obras literárias da época, articulando diversos pontos de vista através dos discursos individuais representados, explorando a intimidade das personagens assim como o olhar de terceiros, justificados por documentos históricos. É o caso de constantes referências a diários, inclusive o do próprio Bonpland na ocasião da viagem que empreendeu com Humboldt, expedição que também é referenciada em manchetes de jornais da época ao noticiarem "A segunda descoberta da América" (p. 108) ou publicarem gravuras dos viajantes. $O$ recurso de cartas também enriquece a prosa, como as de Humboldt para Bonpland ou a da simples "filha do hoteleiro, que tinha lido dois livros", que escreveu a uma amiga de La Rochelle, antes de Bonpland empreender sua primeira viagem à América: “Tem 
uma única roupa muito folgada que tem lustro nas mangas, quando não está catando plantas e mariposas e besouros e pedras e passa todo o tempo no quarto, é médico mas não gosta desse trabalho, acho que não é bem certo da cabeça" (p. 36). Observa-se o modo como a linguagem é reproduzida, simulando a da escrita apropriada a uma moça inculta.

A presença de discursos diretos de Bonpland introduzidos por terceiros é recorrente, especialmente na fase posterior de sua vida, quando, supõe-se, não mais tinha diário. $\mathrm{O}$ discurso direto em diálogos provavelmente não confere tanta ilusão de precisão histórica do que as documentadas por escrito, simuladas em cartas e diários, abrindo-se a alternativa de apresentar a história segundo perspectivas anônimas: "- Eu tenho o desgosto por companhia - disse Aimé Bonpland a alguém." (p. 117). Em certo caso, sobre a prisão no Paraguai, o capítulo é construído com extensos discursos de Bonpland sobre sua permanência no país, em quatro momentos diferentes ao longo de nove anos, sob o signo do testemunho de terceiros: "'Eu soube transformar tudo isto num lugar', diz Don Amado Bonpland a quem o visita no Cerrito. 'Cheguei aqui prisioneiro. Cheguei sem meus livros. Foram queimados pelos homens do doutor Francia.'” (p. 209). O narrador apenas orienta os discursos diretos: "Quatro anos depois, ainda prisioneiro, ele dirá:[...]" (p. 209).

A estruturação do romance orientado a partir do diálogo com AvéLallemant confere um foco considerável na relação entre Bonpland e Humboldt, principal objetivo do explorador, como bem sugerem o título e a capa do romance: a reprodução de uma pintura dos dois na selva da América do Sul, o francês à sombra: "Meu olhar volta-se a Humboldt. [...] Eu, na obscuridade, o observo." (p. 166). Um objeto representativo dessa relação é o Voyage aux Régions Équinoxiales du Nouveau Continent, resultado do trabalho da viagem exploratória que empreenderam. O tema da escrituração de tal livro é resgatado e submetido ao tratamento ficcional, simbolizando, a partir do rompimento de Bonpland em seu trato de escrever a parte sobre a botânica, a mudança ideológica do protagonista, distanciando-se da sombra de Humboldt e de sua teoria pessoal que resultou no trabalho Kosmos, e aproximando-se de um espírito mais romântico. O rompimento da escritura surgiu a partir da estadia no Château de Malmaison, no capítulo "Prisão de vidro", influenciado pela Imperatriz Josefina, que ganha importante papel na vida de Bonpland e por quem ele cultivaria seu amor até morrer, assim como a simbólica rosa Josephina Imperatrix, variação produzida em homenagem a ela. 
A questão do relato biográfico é anunciada ao longo do romance como um meio de cura pessoal, como na ocasião da visita de Bonpland à Santa Casa, sob o efeito do láudano: “Hoje me libertei. Dos venenos do meu corpo. Falta-me, agora. Libertar os venenos da alma. Só vou me livrar delas. Quando narrá-las por inteiro, todas. Mas elas são narradas apenas à margem da morte." (p. 162). Essa cura final efetivar-se-á com a visita de Avé-Lallemant, perspectiva que abre para os dramas pessoais de Bonpland, sua intimidade: “'Mais uma visita' - pensa, ao dobrar a carta. 'Todos querem assistir à minha morte. [...] Em troca de me ver, terá de escutar minha história. Estou pronto para contá-la. Preciso contá-la.'” (p. 244). No entanto, Bonpland relata duas vezes sua história ao visitante, alegando que, sobre a primeira versão, "Tudo que lhe narrei foi falso", questionando a intenção do relato, mesmo sendo "a mesma história, palavra por palavra, frase por frase" (p. 216).

O que importa, doutor, é o sentimento com que as coisas são ditas. [...] Quando lhe contei os fatos da minha vida pela primeira vez, foi pensando no que o senhor diria para o mundo e para a minha Posterioridade; na segunda vez, eu contei tudo debaixo do sentimento da vergonha e do perdão. Eu precisava ser perdoado (p. 247).

Apesar do tom romântico da colocação e da diferença dos relatos idênticos a partir da intenção de quem os profere, o que interessa é a consciência da personagem e a preocupação de sua imagem à posterioridade, ao crivo dos outros. "Uma Posterioridade só existe quando a vida é contada para alguém" (p. 244). Nesse sentido, o romance aborda e questiona a problemática entre o acontecimento e o fato construído sobre o acontecimento, eixo pelo qual é questionada tanto a credibilidade de quem relata diretamente o que aconteceu consigo - "Não me pergunte isso, doutor Martin. E ademais, como o senhor sabe se isso tudo é verdade?" (p. 150) -, bem como a miscelânea de relatos versando outros relatos, os quais distanciam cada vez mais o acontecimento e colorem o mesmo segundo diferentes subjetividades.

A vida de Bonpland, sujeito biológico, é acessível apenas por relatos, de terceiros ou de seu próprio diário, ponto em que é articulada a construção do personagem de modo a questionar a historiografia, uma vez que o historiador articula os relatos e busca neles um sentido através de sua subjetividade, sob determinado "sentimento" inerente ao ser humano e que o impele a escrever. A noção de biografia e memória foge de sua estrutura convencional, uma vez que é arquitetada segundo um narrador onisciente em terceira pessoa, ativo na articulação da miscelânea de 
testemunhos de terceiros e das fontes históricas referidas. Essa aproximação do narrador ao historiador na busca pela legitimação da ficção a partir de referências e dados históricos é, em contrapartida, apenas uma base sobre a qual a intimidade dos personagens ganha espaço, construção ficcional por excelência.

Mesmo apresentando pontos de comunhão com o romance histórico de Lukács e negando certos procedimentos mais radicais próprios das novas modalidades de romance histórico da segunda metade do século XX, Figura na sombra tem uma construção peculiar, o que confere com o depoimento de seu escritor, mencionado no presente estudo. A construção narrativa é rica em sua complexa organização, a qual, sempre através de relatos, coloca o leitor como se em dois tempos (ao menos) em paralelo, o que o envolve e leva-o a uma sensação de envolvimento e veracidade da história.

Assis Brasil, no depoimento exposto anteriormente, alega que o mais importante para ele, atualmente, é a ficção. Parece ser correta tal colocação, no entanto deve-se acrescentar que, não apenas a ficção, o autor tem a preocupação de que a ficção pareça o máximo verossímil em relação à virtual realidade histórica. Nessa busca por uma espécie de aceitação dos fatos pelos leitores, considero curioso o autor ter omitido um episódio extraordinário em relação ao sepultamento de Bonpland: no processo de embalsamento, o corpo foi deixado à porta do recinto destinado a tal finalidade, a desidratar ao sol, quando um bêbado confunde-o com um vivo, cumprimenta-o e, sem resposta, agride o corpo, o que impossibilitou o processo em andamento. Talvez a fonte ${ }^{2}$ não tenha procedência, ou então não interessava ao enredo e suas propostas, mas concorre para a versão recorrente em literatura de que a verdade é mais estranha do que a ficção, pois a ficção precisa fazer sentido - apontamento que serve também para a historiografia.

\section{REFERÊNCIAS}

ARISTOTÉLES. A Poética. Tradução, Prefácio, Introdução, Comentários e Apêndices de Eudoro de Souza. Lisboa: Imprensa Nacional - Casa da Moeda - F. C. S. H. da Universidade Nova de Lisboa, 1986.

BAUMGARTEN, Carlos Alexandre. O novo romance histórico brasileiro. Via atlântica, n. 4, out. 2000.

\footnotetext{
${ }^{2}$ https://pt.wikipedia.org/wiki/Aim\%C3\%A9_Bonpland. Acesso em: 20 jun. 2016.
} 
BRASIL, Luiz Antônio de Assis. Figura na sombra. Porto Alegre: L\&PM, 2012.

BRASIL, Luiz Antônio de Assis. Entrevista com José Pinheiro Torres. Disponível em: http://www.laab.com.br/vida.html. Acesso em: 26 maio 2017.

BURKE, Peter. As fronteiras instáveis entre história e ficção. In: AGUIAR, Flávio et alii (orgs.). Gêneros de fronteira: cruzamentos entre o histórico e o literário. São Paulo: Xamã, 1987.

WEINHARDT, Marilene. A ficção histórica depois de 2010: primeiros apontamentos. Cadernos Literários, v. 23, n. 1, 2015.

HUTCHEON, Linda. Poética do pós-modernismo: história, teoria, ficção. Trad. Ricardo Cruz. Rio de Janeiro: Imago, 1991.

LUKÁCS, György. O romance histórico. Trad. Rubens Enderle. São Paulo: Boitempo, 2011.

MENTON, Seymour. La nueva novela histórica de la América Latina. México: Fondo de la Cultura Económica, 1993.

WIKIPEDIA. Aimé Bonpland. Disponível em: https://pt.wikipedia.org/wiki/Aim\%C3\%A9_Bonpland. Acesso em: 20 jun. 2016.

i E-mail do autor: camiloraabe@hotmail.com 